\title{
Endodontics
}

\section{Endodontic filling removal procedure: an ex vivo comparative study between two rotary techniques}

Mônica Sampaio do Vale Melinna dos Santos Moreno Priscila Macêdo França da Silva Thereza Cristina Farias Botelho

Dental Clinic Department, Dental School, Universidade Federal do Ceará - UFC, Fortaleza, CE, Brazil.

Declaration of Interests: The authors certify that they have no commercial or associative interest that represents a conflict of interest in connection with the manuscript.

\section{Corresponding Author:}

Mônica Sampaio do Vale

E-mail:monicavale@uol.com.br

htrp://dx.doi.org/10.1590/S1806-83242013000600006

Submitted: Mar 04, 2013

Accepted for publication: Jul 31, 2013

Last revision: Aug 09, 2013
Abstract: In this study, we compared the ex vivo removal capacity of two endodontic rotary techniques and determined whether there was a significant quantitative difference in residual material when comparing root thirds. Forty extracted molars were used. The palatal roots were selected, and the canals were prepared using a step-back technique and filled using a lateral condensation technique with gutta-percha points and Endofill sealer. After two weeks of storage in a $0.9 \%$ saline solution at $37^{\circ} \mathrm{C}$ in an oven, the specimens were divided into 2 groups of 20, with group 1 samples subjected to Gates-Glidden drills and group 2 samples subjected to the ProTaper retreatment System. Hedstroem files and eucalyptol solvent were used in both groups to complete the removal procedure. Then, the roots thirds were radiographed and the images were submitted to the NIH ImageJ program to measure the residual filling material in $\mathrm{mm}$. Each root third was related to the total area of the root canals. The data were analyzed using Student's $t$ test. There was a statistically significant difference between the two techniques as more filling material was removed by technique 2 (ProTaper) than technique 1 (Gates-Glidden drills, $p<0.05$ ). The apical third had a greater amount of residual filling material than the cervical and middle thirds, and the difference was statistically significant $(p<0.05)$. None of the selected techniques removed all filling material, and the material was most difficult to remove from the apical third. The ProTaper files removed more material than the Gates-Glidden drills.

Descriptors: Retreatment; Gutta-Percha; Root Canal Obturation.

\section{Introduction}

One of the main goals of endodontic filling is to seal the root canal system to prevent the penetration of liquid tissue, bacteria and/or subproducts, thus preventing reinfection after cleaning and shaping. ${ }^{1}$ Note that the filling quality is directly related to the previous operative steps, such as coronal and chemo-mechanical preparation. When these preparations are not adequate, they will not facilitate the tissue repair process and result in failure of endodontic therapy. ${ }^{2-4}$

Several materials and techniques have been developed to fill root canal systems; however, the gutta-percha substance continues to be the most widely used with sealers. ${ }^{5,6}$

When endodontic therapy fails, the treatment options include retreat- 
ment, endodontic surgery and extraction. ${ }^{2,3}$ Retreatment is preferred over surgical alternatives ${ }^{7,8}$ because this approach is less invasive. The main goal of retreatment is to remove all filling material in the root canal and regain access to the apical foramen, ${ }^{1,2,8-13}$ thereby enabling the insertion of new endodontic procedures ${ }^{2,3,7,10}$ and the subsequent restoration of health of the periapical tissues. ${ }^{7,13,14}$

Insufficient removal of filling material impairs the removal of necrotic tissue or remnant bacteria in the root canal and the reshaping and new filling, which leads to a lasting clinical and radiographic failure. ${ }^{3,7,14}$

The endodontic filling removal techniques vary and include the use of hand files and/or rotary systems, ultrasonic instrumentation and solvent substances, such as eucalyptol, orange oil, and chloroform, to facilitate the removal of filling materials. ${ }^{1-3,7,8,13,15}$

One of the rotary systems developed for this purpose is the ProTaper D1, D2, D3 retreatment system (Maillefer/Dentsply, Balligues, Switzerland). The ProTaper files are made of nickel-titanium alloy and were developed in 2001. ${ }^{3,13}$ These instruments have demonstrated their efficiency, cleaning ability and safety during removal procedures, ${ }^{1-3,14,16}$ although no studies have noted a complete absence of residual filling material following the removal procedure, regardless of the particular tool or strategy used for cleaning the canal. ${ }^{3,16,17}$

Studies have reported on the efficacy of ProTaper files in removing gutta-percha,,$^{2,3,15}$ but there is no consensus among the authors concerning the best endodontic removal procedure. The aim of this study was to compare the removal capacity of endodontic filling when employing the following motor-driven techniques: the ProTaper D1, D2, D3 retreatment system and the Gates-Glidden drills (Maillefer/Dentsply, Petrópolis, Brazil) in an ex vivo study.

\section{Methodology \\ Selection of specimens}

This study was approved by the Ethics Committee of the Universidade Federal do Ceará - UFC (Protocol no. 124/07). Forty freshly extracted human molars were selected for this study. The teeth were stored in $0.9 \%$ saline solution (Gaspar Viana, Petrópolis, Brazil) until use. The crowns were discarded after the teeth were sectioned at the cementoenamel junction with a carborundum disk (Dentorium, New York, USA). The palatal roots were selected, and they had an average length of $16 \mathrm{~mm}$. They were separated from the other roots with a carborundum disk. The working length was fixed at $15 \mathrm{~mm}$ using a Flexofile K file \#08 (Maillefer/Dentsply, Ballaigues, Switzerland).

\section{Root canal preparation}

The root canals were prepared following an endodontic hand file technique using a Flexofile $\mathrm{K}$ file. A \#15 followed by a \#45 (Maillefer/Dentsply, Ballaigues, Switzerland) instrument was used to produce the apical stop $(15 \mathrm{~mm})$ and, during a stepback technique application to the middle and cervical thirds, a \#50, \#55 and \#60 (Maillefer/Dentsply, Ballaigues, Switzerland) order was used in steps of $14 \mathrm{~mm}, 13 \mathrm{~mm}$ and $12 \mathrm{~mm}$, respectively. After use of each file, the final apical file was inserted (file \#45), followed by copious irrigation with $10 \mathrm{~mL}$ of $1 \%$ sodium hypochlorite (Biodinâmica, Ibiporã, Brazil). Finally, the canals were irrigated with $10 \mathrm{~mL}$ of a $0.9 \%$ saline solution.

\section{Filling material and technique}

The root canals were dried with absorbent paper points \#45 (Maillefer/Dentsply, Petrópolis, Brazil) and filled with gutta-percha points (Maillefer/Dentsply, Petrópolis, Brazil) and Endofill ${ }^{\circledR}$ sealer (Maillefer/ Dentsply, Petrópolis, Brazil) using a lateral condensation technique. The quality of the root canal obturation was confirmed by mesiodistal and buccolingual radiographic images (Dabi Atlante, Ribeirão Preto, Brazil), taken with Kodak E-Speed film (Kodak, Rochester, USA) and with settings of $10 \mathrm{~mA}, 60 \mathrm{kV}$, focus-film distance of $10 \mathrm{~cm}$, and exposure time of 0.5 seconds. Obturation quality was considered adequate when there were no empty spaces. After filling, the roots were immersed in a $0.9 \%$ saline solution in Eppendorf tubes (Eppendorf AG, Hamburg, Germany). Then, they were kept in an oven (Olidef CZ, Ribeirão Preto, Brazil) at $37^{\circ} \mathrm{C}$ for two weeks and subsequently subjected to the removal procedure. 


\section{Endodontic filling removal procedure}

The roots were randomly divided into two experimental groups $(n=20)$ according to the techniques employed in the removal procedure. In group 1 , the filling material was removed using technique 1 with Gates-Glidden drills \#2 and \#3 at the cervical and middle thirds, followed by Hedstroem files \#15-45 (Maillefer/Dentsply, Petrópolis, Brazil) to reach working length.

In group 2, the filling material was removed by the Ni-Ti rotary ProTaper Universal D1, D2 and D3 retreatment system using a contra-angle Endo-mate (NSK Inc., Kanuma, Japan) at $350 \mathrm{rpm}$. The filling material in the cervical root third was removed with the D1 instrument (ISO 030) with an active tip, the middle third with the D2 instrument (ISO 25) and the apical third with the D3 instrument (ISO 20). Slight apical pressure was applied, and care was taken to remove the instruments frequently to remove debris from the coils. Finally, Hedstroem files \#1545 were used to reach the working length.

For both techniques, a drop of eucalyptol (Biodinâmica, Ibiporã, Brazil) was used during the early removal procedure and with the Hedstroem files until the instruments could be freely moved into the root canal and the filling material was not perceptible to touch. The removal procedure was considered to be completed when a sequence of files was used to reach the working length and there was no filling material on the stem, and the active part of the last file was used.

\section{Evaluation of residual endodontic material}

Once the filling material had been removed, the roots were radiographed to assess for residual material on the root canals walls. The radiographic images were analyzed using the NIH ImageJ program (National Institute of Health, Bethesda, USA) to measure the residual filling material in each third of the root canal. The linear measurements of the areas filled by gutta-percha and/or sealer remaining in each root third and the total canal area were calculated in $\mathrm{mm}$, and the values were transformed to percentages to measure the amount of filling material that remained after the removal procedure.

\section{Statistical analysis}

Student's $t$ test was used to determine statistically significant differences between the techniques regarding the removal capacity. First, the root thirds in each group were compared. Then, each third of the canals between the groups were compared. Finally, the total areas of the canals were compared to the filling removal capacity between the two groups.

\section{Results}

The residual filling material was evaluated radiographically after the removal procedure using the following scores:

- 0 , absence in all root thirds;

- 1 , presence only in the apical root third;

- 2 , presence only in the middle root third;

- 3 , presence only at the cervical root third;

- 4, presence in the middle and apical root thirds;

- 5 , presence in the apical and cervical root thirds;

- 6, presence in the cervical and middle root thirds; and

- 7 , presence in all root thirds.

After considering the site of the residual filling material in the root canal, the following results were obtained: in group 1, the largest amount of residual filling material was found in the middle and apical thirds (55\%), while in group 2, most of the residual root filling material was found in the apical portion of the root canal $(40 \%$; Table 1$)$.

In this study, $97.5 \%$ of the roots had residual filling material, which was distributed among the cervical, middle and apical root thirds. Only 1 specimen in group 2 had complete removal of filling material $(2.5 \%$ of the sample).

In group 1, 30\% of the cervical root third had residual filling material compared to $35 \%$ in group 2. Residual filling material in the middle root third was found in $75 \%$ of group 1 and $40 \%$ of group 2. Finally, residues in the apical third were found in $95 \%$ of group 1 and $75 \%$ of group 2 (Table 2 ). The results of Student's t-test indicated that there was a statistically significant difference between the apical and the other root thirds $(p<0.05)$.

The root canals of group 1 still had $31.98 \%$ of their total area filled with residual material after the 
Table 1 - Number of specimens and their scores/percentage based on the site of residual filling material in Group 1 and Group 2.

\begin{tabular}{c|c|r|c|r}
\hline Score & $\begin{array}{c}\text { Number of specimens } \\
\text { Group 1 }\end{array}$ & $\%$ & $\begin{array}{c}\text { Number of specimens } \\
\text { Group 2 }\end{array}$ & $\%$ \\
\hline 0 & 0 & 0 & 1 & 5 \\
\hline 1 & 2 & 10 & 8 & 40 \\
\hline 2 & 1 & 5 & 2 & 10 \\
\hline 3 & 0 & 0 & 1 & 5 \\
\hline 4 & 11 & 55 & 2 & 10 \\
\hline 5 & 2 & 10 & 2 & 10 \\
\hline 6 & 0 & 0 & 1 & 5 \\
\hline 7 & 4 & 20 & 3 & 15 \\
\hline Total & 20 & 100 & 20 & 100 \\
\hline
\end{tabular}

removal procedure compared to $18.39 \%$ in group 2. These data indicate that the Gates-Glidden drills left $57.5 \%$ more residual filling material than the ProTaper instruments.

\section{Discussion}

Because of the difficulties in completely removing the endodontic filling material, various techniques for conventional retreatment have been suggested to ensure an effective cleaning of the root canals. ${ }^{6}$ In this study, the selected removal techniques differed in the type of motor-driven instruments employed. Both techniques were performed by a single operator, which is an important factor during the comparison. ${ }^{18}$

Solvents can also be used to dissolve the guttapercha points. Eucalyptol is a colorless solvent with an aromatic odor that is less irritating than chloroform and without carcinogenic potential. Eucalyptol was used in this study because of its efficiency in dissolving gutta-percha points and some sealers, ${ }^{9}$ although Takahashi et al. ${ }^{6}$ in 2009 and Ferreira et al. ${ }^{19}$ in 2006 reported that the use of solvents promotes the formation of a thin layer of softened gutta-percha, which sticks to roots and increases the retreatment time.

Fariniuk et al. ${ }^{11}$ in 2011, Baratto Filho et al. ${ }^{20}$ in 2002 and Imura et al. ${ }^{21}$ in 2000 reported that it was impossible to completely remove all filling material
Table 2 - Percentage of residual filling material in each root third based on the technique used to remove the filling material.

\begin{tabular}{c|c|c}
\hline Root third & Technique 1 (\%) & Technique 2 (\%) \\
\hline Cervical & 30 & 35 \\
\hline Middle & 75 & 40 \\
\hline Apical & 95 & 75 \\
\hline
\end{tabular}

with only rotary instruments. In the present study, the removal procedures in both groups were complemented with a Hedstroem hand file.

In 2012, Li-li Xu et al. ${ }^{12}$ emphasized the importance of hand files for removing filling material. Comparing the ProTaper, the K3 system (Sybron Endo, Orange, USA) and hand files for the removal of debris of dentinal tubules, the latter achieved superior performance.

Different methods can be applied to display the remaining filling material. Radiographic imaging is considered the most efficient method, but it only analyzes the residual material in two dimensions (height and width), thereby preventing the display of the debris thickness. ${ }^{910,22}$ Digital images of longitudinally sectioned roots ${ }^{2}$ can be used to measure the area of remaining filling material inside the canals with the aid of special software ${ }^{2,23}$ and the clarification of the dental technique. ${ }^{24}$

The radiographic method was chosen for this study because it is a viable resource, both experimentally and clinically. However, in 2012, Kfir et al. ${ }^{25}$ reported that radiographic evaluation is not sufficient to detect the entire length of material left inside the canal but that a microscopic evaluation is required to accomplish this.

In this study, the quantitative evaluation of residual endodontic material was obtained by linear measurement of the area filled by the filling material using the NIH ImageJ program.

Our results demonstrate that the apical third had the highest amount of residual endodontic material when compared to the other thirds; the difference was statistically significant, thus corroborating the results by Kaled et al. ${ }^{8}$ in 2011, Somma et al. ${ }^{16}$ in 2008, and Reddy et al. ${ }^{26}$ in 2011, who reported more debris at the apical root third regardless of the 
technique. Our results are in accordance with the report by Bramante et al. ${ }^{27}$ in 2010 that found that the best cleaning was accomplished at the cervical third followed by the middle and apical thirds. They attributed this result to the dental anatomy of this site.

Gates-Glidden drills facilitate the removal of material during the procedure because they push the filling material out of the root canal. ${ }^{27}$ However, this study demonstrated the greater efficacy of ProTaper instruments, which was statistically significant. These differences are most likely attributable to the design of the instruments, as D1, D2 and D3 are made of $\mathrm{Ni}$-Ti and have three progressive tapers and lengths that fit the portions of the cervical, middle and apical root third, respectively. ${ }^{2,3,7}$

According to reports by Giuliani et al. ${ }^{3}$ in 2008, Barrieshi-Nusairin ${ }^{17}$ in 2002, Somma et al. ${ }^{16}$ in 2008, Kfir et al. ${ }^{24}$ in 2012, Gu et al. ${ }^{25}$ in 2008, Reddy et al. ${ }^{26}$ in 2011 and Siotia ${ }^{28}$ in 2011, none of the tested techniques leave root canals completely free

\section{References}

1. Tasdemir T, Yildirim T, Çelik D. Comparative study of removal of current endodontic fillings. J Endod. 2008 Mar;34(3):326-9.

2. Saad AY, AI-Hadlaq SM, Al-Katheeri NH. Efficacy of two rotary NiTi instruments in the removal of gutta-percha during root canal retreatment. J Endod. 2007 Jan;33(1):38-41.

3. Giuliani V, Cocchetti R, Pagavino G. Efficacy of ProTaper universal retreatment files in removing filling materials during root canal retreatment. J Endod. 2008 Nov;34(11):1381-4.

4. Royzenblat A, Goodell GG. Comparison of removal times of thermafil plastic obturators using ProFile rotary instruments at different rotational speeds in moderately curved canals. J Endod. 2007 Mar;33(3):256-8.

5. Cunha RS, De Martin AS, Barros PP, Silva FM, Jacinto RC, Bueno CE. In vitro evaluation of the cleansing working time and analysis of the amount of gutta-percha or resilon remnants in the root canal walls after instrumentation for endodontic retreatment. J Endod. 2007 Dec;33(12):1426-8.

6. Takahashi CM, Cunha RS, Martin AS, Fontana CE, Silveira $\mathrm{CF}$, Bueno CES. In vitro evaluation of the effectiveness of ProTaper universal rotary retreatment system for guttapercha removal with or without a solvent. J Endod. 2009 Nov;35(11):1580-3.

7. Hammad M, Qualtrough A, Silikas N. Three-dimensional evaluation of effectiveness of hand and rotary instrumenta- of gutta-percha and sealer. We obtained similar results in this study. Although our results are in contrast to a report by Schirrmeister et al. ${ }^{10}$ in 2006, which noted a reduction in cleaning at the apical third when ProTaper instruments are used, our results support a study by Saad et al. ${ }^{2}$ in 2007 that indicated the presence of smaller amounts of remaining filling material when a rotary nickel-titanium instrument was used.

\section{Conclusions}

- The ProTaper instruments remove a larger amount of filling material than Gates-Glidden drills at the apical root third.

- None of the techniques completely removed the filling material.

- The apical root third presented the greatest difficulty in removing filling material regardless of the technique.

- The cervical root third filling material was the easiest to remove, regardless of the technique.

tion for retreatment of canals filled with different materials. J Endod. 2008 Nov;34(11):1370-3.

8. Duarte MA, Só MV, Cimadon VB, Zucatto C, Vier-Pelisser FV, Kuga MC. Effectiveness of rotary or manual techniques for removing a 6-year-old filling material. Braz Dent J. 2010;21(2):148-52.

9. Tasdemir T, Er K, Yildirim T, Celik D. Efficacy of three rotary $\mathrm{NiTi}$ instruments in removing gutta-percha from root canals. Int Endod J. 2008 Mar;41(3):191-6.

10. Schirrmeister JF, Wrbas KT, Meyer KM, Altenburger MJ, Hellwig E. Efficacy of different rotary instruments for guttapercha removal in root canal retreatment. J Endod. 2006 May;32(5):469-72.

11. Fariniuk LF, Westphalen VP, Silva-Neto UX, Carneiro E, Baratto Filho F, Fidel SR, et al. Efficacy of five rotary systems versus manual instrumentation during endodontic retreatment. Braz Dent J. 2011;22(4):294-8.

12. Xu LL, Zhang L, Zhou XD, Wang R, Deng YH, Huang DM. Residual filling material in dentinal tubules after gutta-percha removal observed with scanning electron microscopy. J Endod. 2012 Mar;38(3):293-6.

13. Voet KC, Wu MK, Wesselink PR, Shemesh H. Removal of gutta-percha from root canals using the self-adjusting file. J Endod. 2012 Jul;38(7):1004-6. 
14. Huang X, Ling J, Wei X, Gu L. Quantitative evaluation of debris extruded apically by using ProTaper universal tulsa rotary system in endodontic retreatment. J Endod. 2007 Sep;33(9):1102-5.

15. Só MV, Saran C, Magro ML, Vier-Pelisser FV, Munhoz M. Efficacy of ProTaper retreatment system in root canals filled with gutta-percha and two endodontic sealers. J Endod. 2008 Oct;34(10):1223-5.

16. Somma F, Cammarota G, Plotino G, Grande NM, Pameijer $\mathrm{CH}$. The effectiveness of manual and mechanical instrumentation for the retreatment of three different root canal filling materials. J Endod. 2008 Apr;34(4):466-9.

17. Barrieshi-Nusair KM. Gutta-percha retreatment: effectiveness of nickel - titanium rotary instruments versus stainless steel hand files. J Endod. 2002 Jun;28(6):454-6.

18. Imura N, Zuolo ML, Ferreira MO, Novo NF. Effectiveness of the canal finder and hand instrumentation in removal of gutta-percha root fillings during root canal retreatment. Int Endod J. 1996 Nov;29(6):382-6.

19. Ferreira EL, Baratto Filho F, Fidel RA, Fariniuk LF, Rached RN. The performance of ProTaper system during the endodontic retreatment. RSBO. 2006;3(1):64-8.

20. Baratto Filho F, Ferreira EL, Fariniuk LF. Efficiency of the 0.04 taper ProFile during the re-treatment of gutta-perchafilled root canals. Int Endod J. 2002 Aug;35(8):651-4.

21. Imura N, Kato AS, Hata GI, Uemura M, Toda T, Weine F. A comparison of the relative efficacies of four hand and rotary instrumentation techniques during endodontic retreatment. Int Endod J. 2000 Jul;33(4):361-6.

22. Ferreira JJ, Rhodes JS, Ford TR. The efficacy of gutta-percha removal using Profiles. Int Endod J. 2001 Jun;34(4):267-74.

23. Bramante CM, Betti LV. Efficacy of Quantec rotary instruments for gutta-percha removal. Int Endod J. 2000 Sep;33(5):463-7.

24. Gu LS, Ling JQ, Wei X, Huang XY. Efficacy of ProTaper Universal rotary retreatment system for gutta-percha removal from root canals. Int Endod J. 2008 Apr;41(4):288-95.

25. Kfir A, Tsesis I, Yakirevich E, Matalon S, Abramovitz I. The efficacy of five techniques for removing root filling material: microscopic versus radiographic evaluation. Int Endod J. 2012 Jan;45(1):35-41.

26. Reddy S, Neelakantan P, Saghiri MA, Lotfi M, Subbarao CV, Garcia-Godoy F, et al. Removal of gutta-percha/zinc-oxide eugenol sealer or gutta-percha/epoxy resin sealer from severely curved canals: an in vitro study. Int J Dent. 2011;2011:541831.

27. Bramante CM, Fidelis NS, Assumpção TS, Bernardineli N, Garcia RB, Bramante AS, et al. Heat release, time required, and cleaning ability of Mtwo R and ProTaper Universal retreatment systems in the removal of filling material. J Endod. 2010 Nov;36(11):1870-3.

28. Siotia J, Acharya SR, Gupta SK. Efficacy of ProTaper retreatment system in root canals obturated with Gutta-Percha using two different sealers and guttaflow. Int J Dent .2011;2011:676128. 